\title{
EVOLUTION OF THE URBAN WASTE MANAGEMENT SYSTEM IN THE EMILIA-ROMAGNA REGION
}

\author{
Chiara Magrini ${ }^{1, *}$, Giovanni Biagini ${ }^{2}$, Francesca Bellaera ${ }^{3}$, Leonardo Palumbo ${ }^{3}$ and \\ Alessandra Bonoli ${ }^{1}$ \\ ${ }^{1}$ Department of Civil, Chemical, Environmental and Materials Engineering-DICAM/University of Bologna, via Terracini 28,40131 Bologna, \\ Italy \\ ${ }^{2}$ Agenzia Territoriale dell'Emilia-Romagna per i servizi idrici e rifiuti (ATERSIR), Via Cairoli 8/F, 40121 Bologna, Italy \\ ${ }^{3}$ Regione Emilia-Romagna, Servizio giuridico dell'ambiente, rifiuti, bonifica siti contaminati e servizi pubblici ambientali, Viale della \\ Fiera 8, 40127 Bologna, Italy
}

Article Info:

Received:

29 July 2020

Revised:

23 February 2021

Accepted:

22 March 2021

Available online:

27 May 2021

Keywords:

Waste management

Waste prevention

Waste authority

Regulation

Emilia-Romagna region

\begin{abstract}
This multidisciplinary study aims to analyse how the urban waste management system has changed in the Italian region of Emilia-Romagna, during the decade in which a single regional regulatory unit, the Emilia-Romagna Territorial Agency for Water and Waste Services (ATERSIR), was established and became operational, and the waste management planning was centralized at regional level. Particularly, the following changes have been analysed: i) the methods of municipal waste management (WM), considering waste generation, separate waste collection and waste treatment; ii) the costs of WM service, with a focus on cost of treatment and disposal of unsorted waste; and iii) the urban solid WM policies, in terms of levels of governance, territorial planning and implementation of policies on the regional territory. The period within which the analysis was carried out covers the years from 2008 to 2018, comparing two time frames, before and after ATERSIR establishment. Data at municipal level were gathered and analysed. The results of the technical, economical and institutional assessment show that relevant benefits occurred, such as a constant improvement of environmental performances, the optimisation of the waste flows to plants, a higher level of uniformity of WM cost among Municipalities and a better quality of data collected from waste providers for the technical and economic regulation of the sector. Potential improvements are identified, whilst the institutional reform is positively evaluated in all the analysed aspects.
\end{abstract}

\section{INTRODUCTION}

Waste services are considered of public and general economic interest since they are essential to human comfort, public health and environmental quality, and since they are key elements for economy's competitiveness and society's overall well-being (Hoornweg and Bhada-Tata, 2012; Marques et al., 2018).

As argued by Campitelli and Schebek (2020), who reviewed 366 studies on waste management systems (WMSs) of cities or countries and focused on municipal solid waste (MSW), the assessment of WMSs is a crucial and still relevant topic, according to the increasing number of publications in the last 40 years. In recent years, the public interest associated with municipal waste management (MWM) has broadened, as it is concerned with much more far-reaching sustainability issues: materials consumption, availability of disposal sites, pollution from treatment cycles (Antonioli and Massarutto, 2011). According to Campitelli and Schebek (2020), besides environmental, organizational, and technical aspects, many studies have considered other aspects, in compliance with the increasing demand for broader sustainability assessment, where the environment, society and the economy are integrated (Hellweg and Canals, 2014). Furthermore, governance aspects have gained attention. Indeed, the governance is crucial for building up a WMS (Filho et al., 2016) and the institutional framework should be well designed in order to ensure the quality of the service and its environmental and economic sustainability.

In addition to technical and quality of the service regulation, most literature agree on the need of economic regulation in the waste sector in many different countries, as the sector can be subject to inefficient conditions due to market failures and lack of incentives (Di Foggia and Beccarello, 2020a; Sarra et al., 2020; Marques et al., 
2018; Simões and Marques, 2012a; Simões and Marques, $2012 b)$. Besides promoting the implementation of the principle of economic and financial sustainability and ensuring the suitability of fee structures at national, regional, or local levels (Marques et al., 2018), the role of economic regulation in enhancing the quality of the service (Marques and Simões, 2009; Simões and Marques, 2012a) and promoting the implementation of circular economy (CE) principles (Di Foggia and Beccarello, 2020a) is also recognised.

An extensive literature on the optimal operational size of (private or public) waste service providers is available: the impact of territorial scale on the efficiency and on the achievement of economies of scale and scope, both for waste collection providers and for owners of waste treatment or recycling plants, was debated (Stevens, 1978; Antonioli and Filippini, 2002; Simões et al., 2013; Abrate et al., 2014; Carvalho and Marques, 2014; Carvalho et al., 2015; Tanguy et al., 2017). Other studies discussed the optimal extension of the area to be served by single operators and the variables which should be considered to select Municipalities thereinto by adopting the perspective of regulatory authorities (Sarra et al., 2017; Sarra et al., 2020).

To the best of our knowledge, no studies have discussed the optimal territorial scope under the responsibility of a single economic regulation authority (i.e., in terms of number of service providers, or geographical extension), or the impacts on WMSs caused by a reform of the institutional structure. This study has the ambition to contribute to such discussion, through an analysis of the evolution of a MWM system in the Italian region of Emilia-Romagna, over the period 2008-2018.

In 2011, thanks to an internal reform, the Emilia-Romagna Region started to strengthen its role in the planning and regulation of urban WM services. The objective of this research paper is to study what impacts this transition had on the management of solid urban waste (UW). The analysis of variables directly affected by the economic regulation is complemented by an assessment of environmental and institutional aspects, to study the joint effects and the synergies between WM planning and economic regulation itself. This is a novelty, since the effects of economic regulation are usually evaluated in terms of effectiveness, efficiency, or productivity of providers, while neglecting an in-deep analysis of the locally pursued WM strategies. This partial approach might deliver misleading messages for decision makers, since achieving CE objectives might hinder efficiency of waste service operators, as highlighted by Di Foggia and Beccarello (2020b). Moreover, the territorial dimension suitable for the implementation of $\mathrm{CE}$ might be bigger than the area served by single operators.

Thus, since in the Emilia-Romagna region the CE policies are at the core of regional waste management planning, this study attempts to analyse how an institutional reform has affected these aspects. Particular attention is given to the analysis of the homogeneity level of performances among Municipalities in the region, as its increase is an objective of public policies and it might result from a centralised regulation.

\section{MUNICIPAL WASTE MANAGEMENT IN THE EMILIA-ROMAGNA REGION}

Emilia-Romagna is a region in Northern Italy that extends inland westward from the Adriatic coast, with a population equal to 4.459.477 inhabitants (2019). Emilia-Romagna is one of the wealthiest and most developed regions in Europe; it was the third wealthiest region in Italy in 2017, considering the indicator "primary income of private households". The region is divided in 9 Provinces (Figure S1) and it includes 328 Municipalities (2019). In the same Figure S1, the MSW providers are also shown. The service providers in the Region remained almost the same over the analysed years (2008-2018).

\subsection{Regulation of municipal waste management}

In Italy, the public service regime applies to municipal waste, including household waste, orphan waste and a fraction of industrial and commercial waste, while the market regime applies to the remaining of commercial and business waste (special waste).

As a local public service, the municipal solid waste (MSW) management is regulated by a multilevel regulatory asset, organized in a central, national authority (ARERA, Italian Regulatory Authority for Energy, Networks and Environment), a secondary level, organized in areas defined by each Region, often corresponding to Italian provinces, and a municipal level, still important in the institutional framework and in the different institutional roles.

Focusing on the secondary level, since the beginning of the 1990s', the management of local public services, and particularly water and wastewater services and MWM, was delegated to a new over-municipal structure, called Optimal Territorial Area (OTA), a territorial partition specifically designed to exploit fully economies of scale/scope/density (Massarutto, 2010). A single authority for each OTA (on the board of which all the municipalities that make it up were represented) was responsible for the choices made to organize/coordinate the entire waste cycle (public management, private management or public-private partnership, concession to operate the services, tariffs, etc.) (Sarra et al., 2017). The aim was the improvement in efficiency and effectiveness of the previous municipal-based providers, by applying a more industrial approach to the service and promoting managerial integration among the different activities involved in the waste cycle. As far as the Emilia-Romagna Region is concerned, the OTAs were set in 1999, with a provincial dimension. Therefore, nine different regulatory agencies were defined in the region.

Nowadays, the economic regulation of the Italian MSW is scattered in various regional scenarios. The regulatory agencies, defined by each Region, can have the same size of the region (for example, Emilia-Romagna), a multi-province dimension (as it happens in Toscana Region) or even do not exist at all. In the last case, single Municipalities, or small associations of few Municipalities, are in charge of the MSW collection and treatment service (Biagini, 2016).

According to Italian law, the identification of the optimal size for the organization of the waste service must be 
based on the application of the following criteria (Legislative Decree 152/2006, art. 200):

- overcoming the fragmentation through an integrated WM service;

- achievement of adequate management dimensions, defined on the basis of physical, demographic, and technical parameters, and considering the political-administrative subdivisions;

- appropriate evaluation of the transportation systems, in order to optimise the transport within the OTA;

- exploitation of common needs and similarities in waste production and management;

- reconnaissance of WM plants already built and in operation;

- consideration of previous delimitations, so that new OTAs deviate from previous ones only on the basis of justified requirements of effectiveness, efficiency, and affordability.

Furthermore, the principle of proximity of the places of waste production to recovery and disposal plants should be considered. Additionally, the achievement of self-sufficiency in disposal, within the region, is recommended, in order to reduce movements of waste, taking into account the geographical and social context or the need for specialized plants for certain types of waste (Legislative Decree 152/2006 art. 182-bis).

It is worth noting that "optimal organizational size" and "optimal managerial size" do not always coincide. Thus, according to Article 34 of Law 221/2012, the OTA authority is not obliged to entrust the management of the collection service to a single operator. Indeed, an OTA itself can be divided into multiple sub-areas (service-specific optimal territorial areas, or SOTAs) if specific services (collection, treatment, etc.) can achieve economic efficiency at smaller territorial scales, and several operators can be entrusted with the service, one for each SOTA, under the supervision of the OTA authority, which guarantees the coherence of the whole system (Sarra et al., 2017).

In 2011, with the regional Law 23/2011, the Emilia-Romagna region reformed the regulatory architecture of the OTAs: a new unique regional OTA was defined, and at the same time, a new institution, the "Emilia-Romagna territorial agency for the water, sanitation and waste services", (or ATERSIR, in the Italian acronym) was established, dismissing the provincial ones (Emilia-Romagna Region, 2011). From an administrative point of view, the new regional agency was set up at an intermediate level between the strictly local level and the national one.

So, since 2012 ATERSIR has been responsible for the economic regulation of the MWM. Its main tasks are those expected by the national legislative framework: economic regulation of the service; financial and economic planning; entrusting MWM service; verifying that the services are fully compliant with the European framework directives on competition; planning and scheduling projects finalized to comply with the European and Italian environmental performances and quality standards.
The governance was structured at two administrative levels: a regional board assuming the main functions and responsibilities and nine local councils of provincial (sub-regional) dimension (Biagini, 2016).

Following Massarutto (2010), in the value chain of MWM three main phases can be identified, which give rise to three distinct markets. The first one concerns collection service, whose counterparts are waste producers and operators. The second is the market for the handling and disposal of waste, whose counterparts are operators of collection services and owners of disposal sites. The third is recovery/recycling, whose counterparts are again collection operators and final users of waste-derived materials. In this framework, ATERSIR regulates the collection services and the unsorted waste treatment and final destination (waste-to-energy (WTE) plants and landfills), while for the third phase mentioned above, the Agency ensures and supervises the application of the best treatment prices. In particular, since 2014, accordingly to a specific regional regulation, ATERSIR has performed the regulation of "gate fees" for the treatment plants for unsorted UW, i.e., WTE plants, mechanical-biological treatment plants and landfills.

In Emilia-Romagna, UW service is managed by 11 different providers (2019). ATERSIR, managing 18 contracts, approves each year the financial plans for each single municipality for a total amount of approximately $€ 750.000 .000$.

\subsection{Regional legislation and planning of waste man- agement system}

In Italy, responsibility for environmental policies is held by the national government, but the regional government is the responsible authority for the Waste Management Plan (Legislative Decree 152/2006, art. 199). In the General Direction for Environment and for Soil and Coast protection of Emilia-Romagna Region, a specific team works on the implementation of objectives for a sustainable WM.

In 2011, the transition from 9 OTAs to one regional OTA implied the transition from 9 Provincial WM Plans to a single Regional WM Plan, given that the planning function had been delegated to the Provinces in previous years.

In the "WM plan of Emilia-Romagna Region", definitively approved in May 2016, the Region defined the strategic objectives for sustainable WM, in line with the European hierarchy which puts prevention and recycling first. The plan includes a prevention programme, with a time frame of 7 years (2013-2020); a lot of typologies of waste prevention measures are set, with impact on different product life stages (Magrini et al., 2021). Before 2012, indeed, the implementation of waste prevention programmes was on voluntary basis, and only few provinces had implemented waste prevention policies in their territory.

Furthermore, as promoted by European policies, Emilia-Romagna was the first Italian region to assume the CE principles in its waste policy by law, with the aim of reducing waste production and recovering as much material as possible for recycling. 
The Regional Law 16/2015 explicitly introduces a new concept of "sustainable development", assuming that the winning approach is the one which tends towards a holistic, comprehensive, and not sectorial vision. The transition to a more CE offers great opportunities for development with resulting advantages in economic terms (i.e., employment, competitiveness), as well as energy savings and environmental benefits. Moreover, the Regional Law 16/2015 defines targets for waste prevention and management, to be achieved by 2020 :

- reduction in per capita waste generation by $15 \%-20 \%$, compared to the 2011 values, mainly through the implementation of Pay-as-you-throw (PAYT) systems;

- annual per capita amount of UW not sent for recycling not exceeding 150 kilograms per inhabitant;

- $73 \%$ of separate waste collection rate at regional level, differentiated for homogeneous area;

- recycling of paper, metals, plastic, wood, glass and organic waste by at least $70 \%$;

- self-sufficiency in the disposal of non-hazardous municipal and special waste at regional level, through the optimal use of existing facilities;

- minimisation of disposal, in particular landfill.

Emilia-Romagna presents a rather uniform socioeconomic situation, but it has a variety of geographic, urban and WM characteristics (Passarini et al., 2011). The creation of a regional governance made possible the grouping of similar municipalities (Figure 1): the entire regional territory was divided into three "homogeneous areas", identified by crossing physical-geographical factors (geomorphological elements, altimetry) with human-related factors and WM characteristics (population density, percentage of separate collection already achieved).
At last, it is important to underline that the regional WM plan has been monitored yearly, in order to be reactive to any need that might arise from the municipalities.

\section{MATERIALS AND METHODS}

\subsection{Methodology of the assessment}

The methodology used in this study included the selection and calculation of some quantitative indicators, as well as a qualitative assessment, to assess technical, environmental, economic, and institutional aspects of the regional WMS. Since specific aim is the analysis of the evolution of the homogeneity level of performances among the Municipalities in the region, over the time frame 2008-2018, the average and the standard deviation of some indicators calculated at municipal level were also assessed.

As far as technical and environmental aspects are concerned, three stages of integrated WMS were analysed: waste generation, separate waste collection and waste treatment. The main targets set by policies were evaluated.

With growing concerns about the economic sustainability of waste services, a number of studies focused on their cost structure. The authors chose to analyse the total cost of WM and provide a focus on cost of treatment and disposal of unsorted waste (CTS, in the Italian acronym, according to the national law D.P.R. 158/1999).

The analyses were carried out, if possible and relevant, by comparing two different time frames in order to illustrate the level of some indicators before (2008-2012) and after (2013-2018) the governance reform process and the unique OTA establishment. As an exception to this rule, the analyses on the costs of treatment and disposal of unsorted waste considered two different time frames (2008-2013 and 2014-2018) since in 2014 the regional legislation reg-

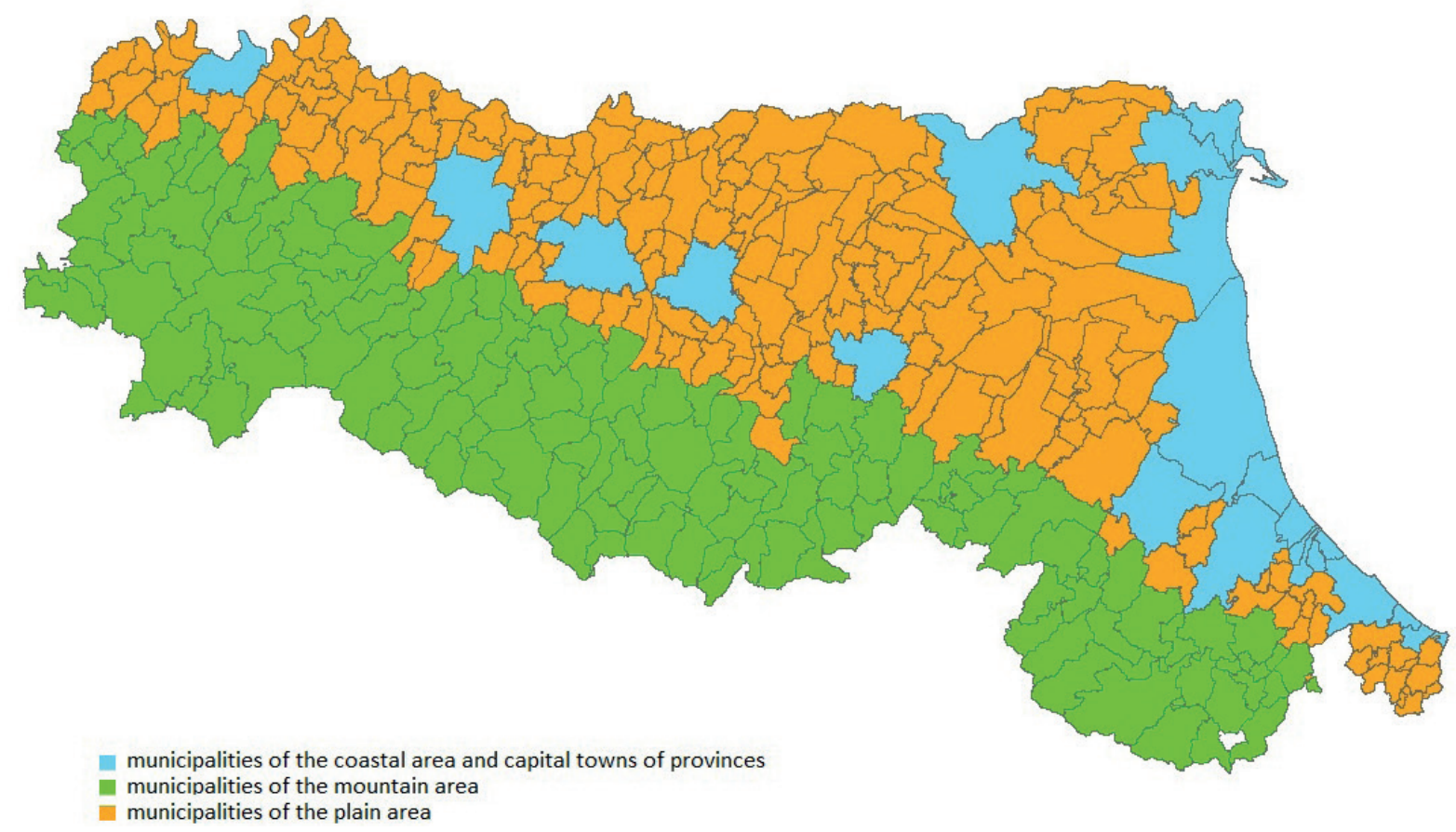

FIGURE 1: Municipalities of Emilia-Romagna region, clustered by “homogeneous areas”. Source: Emilia-Romagna Region, 2016. 
ulating the disposal fee was applied for the first time. The economic performances of the Emilia-Romagna region were compared to the ones of other Italian Regions, selected according to some relevant criteria:

- similar geographical position and economic situation;

- presence of an operating regulatory agency, according to Invitalia (2019). Further details are provided by Table S1.

The selected Regions are: Lombardia, Veneto, Toscana, Umbria, Friuli-Venezia Giulia, Liguria, Marche and Province of Trento. It should be noticed that Lombardia was selected, despite not having an operating regulatory agency, as it represents an alternative model, compared to Emilia-Romagna. Nevertheless, it should be noticed that Emilia-Romagna is the only Region which regulates waste treatment fees.

Finally, some relevant aspects of the institutional assessment were selected and some consequences of a regionally unified regulatory agency for the MSW management, together with a unique regional planning were discussed.

\subsection{Data sources}

Data for each Municipality in the Emilia-Romagna region were gathered, referring to the time frame 2008-2018. In particular, the following data sets were systematised:

- generation of sorted and unsorted waste;

- resident population;

- economic data (i.e., total cost of the service and CTS).

On the other hand, data on WM (waste sent to landfill and incineration, recycling rates) were gathered and analysed on a regional scale per single year. The data sources were the Emilia-Romagna region, the Regional Agency for Prevention, Environment and Energy (ARPAE), and ATERSIR.

As far as economic data are concerned, a demanding historical research and data systematisation activity were necessary. Economic data indeed were collected from the databases of the provincial OTAs or from ATERSIR database, if referred to the period from 2008 to 2011 or from 2012 to 2018 respectively. Data from the municipal economic-financial plans were mainly used: these plans aim to estimate the costs of the service which contribute to establish the fees for the users. If this value was not available, data were gathered from a regional database, which usually reports real costs, instead of the planned ones. Details on the number of Municipalities considered in the economic assessment are available in Table S2, which also details the number and percentage of Municipalities whose data do not come from financial-economic plans, but from the regional database.

To compare the regional system with either the national one or the one of other Regions, data made publicly available by the Italian National Institute for Environmental Protection and Research (ISPRA) were used (ISPRA, 2019; ISPRA, 2020a; ISPRA, 2020b).

\section{RESULTS AND DISCUSSION}

\subsection{Technical and environmental assessment}

\subsubsection{Waste generation}

Table 1 shows the total UW and unsorted UW generation, waste generation per capita, at regional level, in the analysed period from 2008 to 2018 . The regional legislative approach and regulation seem to have a limited impact on the decrease of the total amount of waste production, over the time frame analysed. On the other hand, the regional policies and the institutional framework led to a considerable and constant reduction of unsorted waste production.

As shown in Figure S2, per capita UW generation in Emilia-Romagna was significantly higher than the average Italian value in all the eleven years of analysis. The critical factors are structural and related to:

the economic situation: the Region is one of the most economically developed and flourishing areas in Italy. The direct correlation between waste generation and the main economic indicators, such as gross domes-

TABLE 1: Evolution of total urban waste production and per capita production in the Emilia-Romagna region. Source: authors' elaboration based on Emilia-Romagna Region data.

\begin{tabular}{|c|c|c|c|c|c|}
\hline Year & $\begin{array}{l}\text { Urban waste generation } \\
\text { [tonnes] }\end{array}$ & $\begin{array}{l}\text { Unsorted urban waste } \\
\text { generation [tonnes] }\end{array}$ & Inhabitants & $\begin{array}{l}\text { Per capita urban waste } \\
\text { generation [kg/inhab] }\end{array}$ & $\begin{array}{l}\text { Per capita unsorted urban } \\
\text { waste generation [kg/inhab] }\end{array}$ \\
\hline 2008 & 3.013 .721 & 1.646 .404 & 4.337 .966 & 694,73 & 379,54 \\
\hline 2009 & 2.987 .477 & 1571.876 & $4.377 .473^{1}$ & 682,47 & 359,08 \\
\hline 2010 & 3.093 .089 & 1.535 .054 & 4.432 .439 & 697,83 & 346,32 \\
\hline 2011 & 3.002 .771 & 1415.337 & 4.459 .246 & 673,38 & 317,39 \\
\hline 2012 & 2.893 .518 & 1.334 .030 & 4.471 .490 & 647,10 & 298,34 \\
\hline 2013 & 2.896 .432 & 1.268 .472 & 4.453 .435 & 650,38 & 284,83 \\
\hline 2014 & 2.929 .953 & 1.223 .344 & 4.457 .115 & 657,37 & 274,47 \\
\hline 2015 & 2.962 .076 & 1.165 .311 & 4.454 .393 & 664,98 & 261,61 \\
\hline 2016 & 2.969 .293 & 1.132 .866 & 4.457 .318 & 666,16 & 254,16 \\
\hline 2017 & 2.895 .720 & 1.034 .832 & 4.461 .612 & 649,03 & 231,94 \\
\hline 2018 & 3.011 .354 & 964.693 & 4.471 .485 & 673,46 & 215,74 \\
\hline
\end{tabular}

${ }^{1}$ The geographical area of the region changed in 2009, as 7 Municipalities were annexed from Marche region. 
tic product, is well known. As shown in Figure S2, indeed, the economic crisis influenced waste production both at national and regional level, contributing to the decrease of the total amount of UW generated in 2009 compared to 2008, despite the annexation of 7 new Municipalities to the region.

- the categories of waste assimilated to UW: Emilia-Romagna WM is overall characterized by a high amount of commercial/industrial waste assimilated to UW, also due to a productive network strongly connected to the urban one and to the plant engineering capacity present on the territory. This made it possible to manage the assimilated waste in complete safety and to guarantee its traceability, while containing the tariffs applied to domestic and non-domestic users;

- tourist flows: in Emilia-Romagna in 2018, there were 11.458.497 visitor arrivals and 40.647.799 guests in hotels and complementary structures, with an average length of stay of 3,55 days, mainly in the provinces of Rimini, Ravenna and Forli-Cesena (for details, see Table S3). The values of the per capita waste generation indicator and per capita unsorted waste generation for these Provinces are among the highest in the region (Figure S3 and S4).

Analysing data on waste generation at municipal level, the average and the standard deviation of per capita total waste generation, per capita sorted and unsorted waste generation for each considered year were calculated (Figure 2). Even if a decrease in the average value of per capita unsorted waste and an increase in the average value of per capita sorted waste occurred, the standard deviation did not decreased and the performances of the Municipalities did not become more homogenous over the years of analysis. The reasons for this can be found in the peculiarities of Municipalities, mainly in terms of assimilation and tourist flows.

The dataset could be more homogeneous (with a lower standard deviation) considering not only the resident inhab- itants, but the parameter "Inhabitant Equivalent", introduced by Regional Law 16/2015 in order to make the performance of municipalities comparable in terms of MSW production. For each Municipality, this parameter is calculated, year by year, as the sum of contributions related to different quantities: resident citizens, non-resident households, university students, tourist flows, productive activities.

Moreover, the variation of per capita waste production at municipal level was studied, over the two above-mentioned time frames. The results show that the number of Municipalities which recorded an increase of this indicator (negative variation in $\mathrm{x}$-axis) is higher over the second time frame than over the first one (Figure S5 and S6). The same results are shown if the analysis is repeated on per capita unsorted waste generation, applying the same methodology (Figure S7 and S8). Further research is needed to fully understand the reasons behind these performances.

Within the scope of this research paper, the effects of PAYT schemes on waste production were not studied. The number of Municipalities which implemented PAYT schemes increased from zero to 60 over the 2008-2018 decade.

\subsubsection{Separate waste collection}

The separate collection rate in the Region increased steadily over the analysed decade, from $45.4 \%$ in 2008 to $68 \%$ in 2018 . The increase was also constant on a national scale, going from $30.6 \%$ in 2008 to $58.1 \%$ in 2018 (Figure S9).

The reform of the institutional framework in 2011/2012 did not transform the trend, but a significant improvement occurred: the separate collection rate increased $9,4 \%$ between 2008 and 2012, while in the second time frame (2013-2018) the increase rate was 15,8\%. Given that the more separate collection rate rises, the harder is to achieve further improvements, this data is a really important result and proves the regional commitment on the improvement of separate waste collection.

The separate collection rate over the period 2008-2018

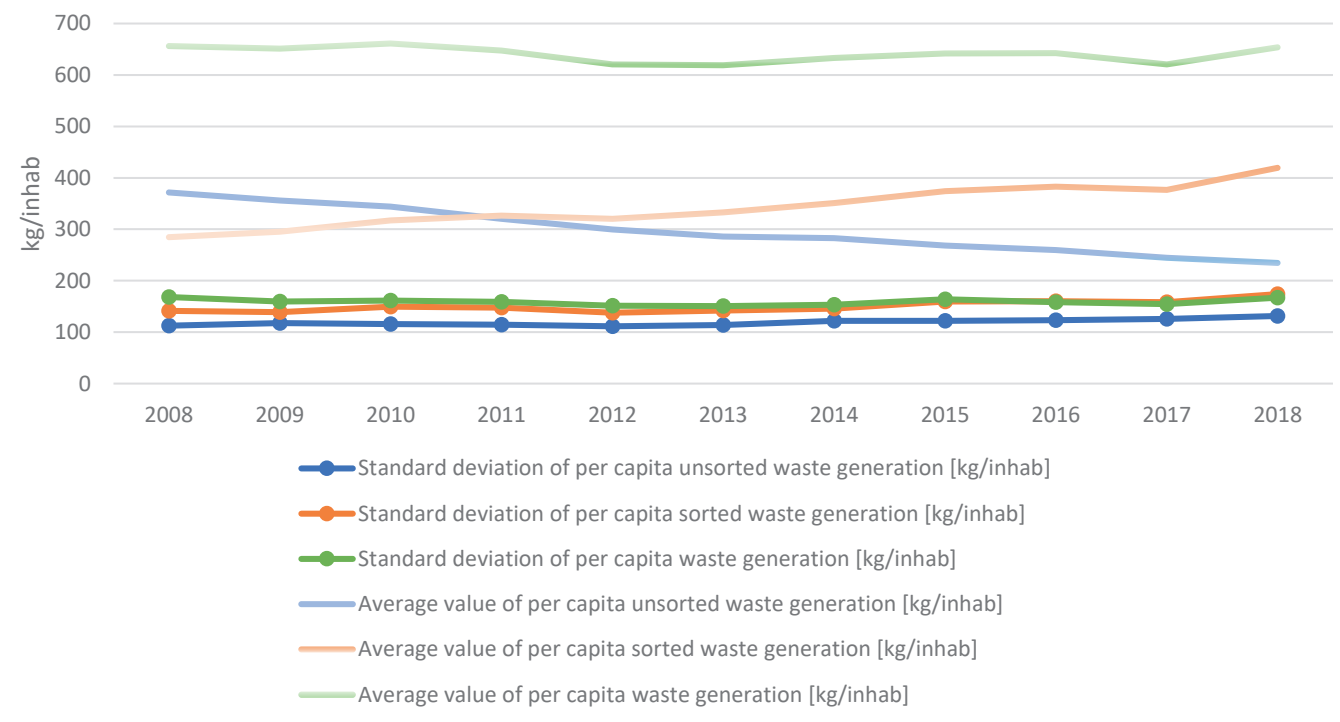

FIGURE 2: Average and standard deviation of per capita sorted and unsorted waste generation at Municipal level. Source: authors' elaboration based on Emilia-Romagna Region data. 
in the three homogeneous areas had the same trend as the regional one (Figure S10). Given that the target for this indicator is different for each Municipality according to the relevant homogeneous area the average value and the standard deviation were not analysed.

Furthermore, the percentage variation of separate waste collection rate at municipal level was studied, focusing on two time frames: 2008-2012 and 2013-2018. Considering the availability of data, two samples of 341 and 321 Municipalities were object of analysis in the two time frames respectively. The results show that in the second time frame the number of Municipalities achieving a good performance in separate collection increased, as well as the number of Municipalities with a positive trend of the separate collection rate (Figure 3 and Figure 4, where each dot represents a Municipality). A deeper analysis is required to understand the reasons of the values of outliers Municipalities.

\subsubsection{Waste treatment}

Even if the collection rate is often used in the assessment of effectiveness of waste service (e.g. CNEL, 2019),

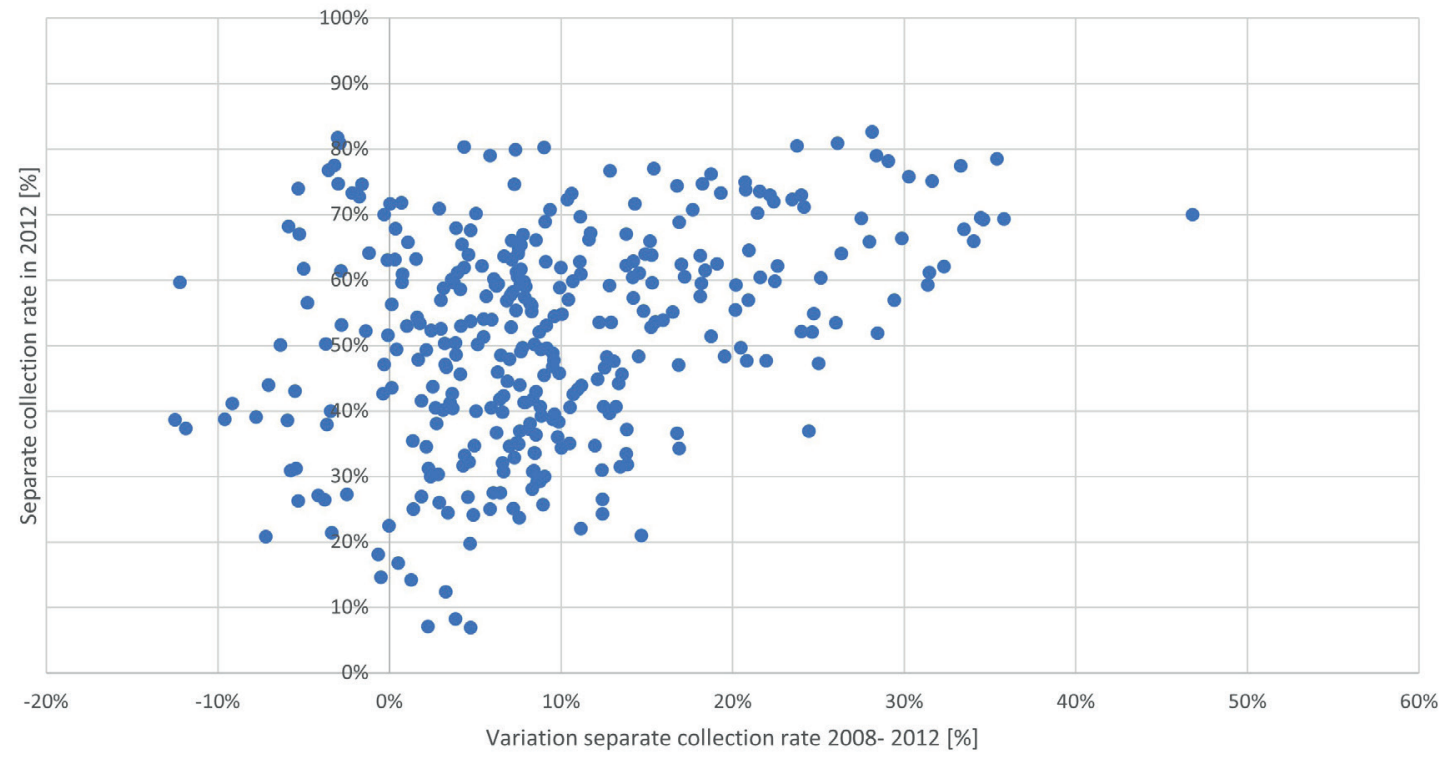

FIGURE 3: Variation of separate collection rate (2008-2012) and separate collection rate (2012), for each Municipality in the Emilia-Romagna region. A negative variation (x-axis) represents a decrease in the separate collection rate over years. Source: authors' elaboration based on Emilia-Romagna Region data.

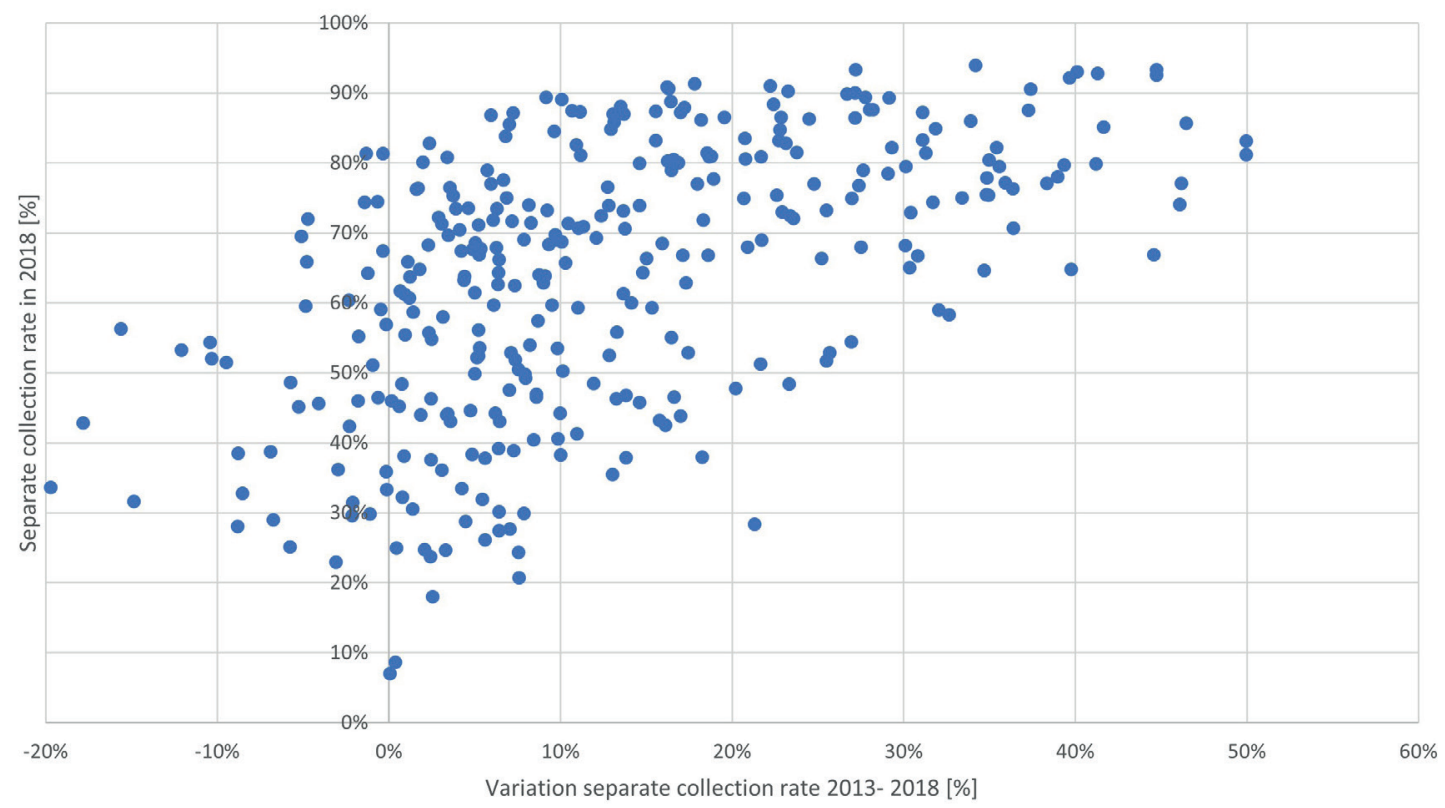

FIGURE 4: Variation of separate collection rate (2013-2018) and separate collection rate (2018), for each Municipality in the Emilia-Romagna region. A negative variation ( $x$-axis) represents a decrease in the separate collection rate over years. Source: authors' elaboration based on Emilia-Romagna Region data. 
other aspects of waste service performances should be taken into account in order to assess the compliance with the regulatory framework.

In the region, landfill use constantly decreased over the eleven years analysed: the overall landfill rate in 2018 was $2,79 \%$, already well below the target of $10 \%$ by 2035 set out in European Directive 851/2018, and below the Italian rate (Figure S11). No substantial changes in trends can be observed when comparing the time frames 2008-2012 and 2013-2018 (decrease by $12,65 \%$ over the first time frame, and by $13,28 \%$ over the second one). Landfill diversion was achieved through a combination of strategies, applying the European waste hierarchy and promoting prevention, recycling and WTE plants. As Antonioli and Massarutto (2011) inferred from the analysis of landfill reduction in 8 European Countries over the period 1995-2005, significant diversion rate can be achieved only where all strategies (recycling, indirect material recovery, waste-to-energy) are combined, while strategies concentrated on sole recycling, despite some success at local scale, do not seem to be able to perform at the scale of the overall system.

Emilia-Romagna extensively uses WTE plants, achieving an incineration rate higher than the national one (Figure S12). The amount of UW sent to incineration or used for the production of refuse derived fuel (RDF) in the region increased at a constant rate over the analysed time frame: it increased by $4,89 \%$ over the time frame 2008-2012, and by $3,87 \%$ over the period $2013-2018$.

Considering sorted waste destination/treatment, the regional recycling rate for some waste flows, in the period 2014-2018, and the total recycling rate at regional and national level were analysed (Figure S13). Because of regional data availability, it was not possible to elaborate the indicator for previous years. According to annex 1 of European Commission Decision 2011/753/EU, the calculation method 2 was applied, as also suggested by the Italian Ministry of environment, land and sea. Thus, the ratio between the recycled amount of paper, metal, plastic, glass waste and other single waste streams from households or similar waste stream, and the total generated amount of the same waste streams was calculated.
No considerations on waste treatment at municipal level can be drawn.

\subsection{Economic assessment}

\subsubsection{Total cost of waste management}

Firstly, the amount of management costs of the urban hygiene service covered by institutional entities (Municipalities, their Consortia and other service managers) were considered, as reported by ISPRA. Because of data availability, the cost of WM has been evaluated in the period 2011-2018. The comparison between the average regional and national costs of WM highlights that Emilia-Romagna has an efficient management of UW, considering the ratio between costs and quantities of waste (Figures S14 and S15). Per capita costs grew, correspondingly to the national average value, while costs per tonne remained fairly constant after 2014. Moreover, the average "per tonne cost of WM" at regional level was lower than the one of almost all the selected Regions in the period 2011-2018 (Figure S16), while the standard deviation of the same indicator assessed at municipal level remained fairly stable, compared to the one of the other Regions (Figure S17).

Secondly, an analysis of the municipal economic-financial plans officially approved by the regulatory authorities was performed, for the time frame 2008-2018, calculating WM cost per resident inhabitant and per tonne of generated waste. Figure 5 shows the evolution of the indicators on regional WM cost. The change in the institutional structure seems to have impact on the growth trend of the total costs of the service, by containing the increase over time: while an increase in the cost per inhabitant and per tonne by $11 \%$ and $19 \%$ respectively occurred between 2008 and 2012 , the indicators increased $7 \%$ and $3 \%$ respectively in the period between 2013 and 2018 .

Then, analysing the costs at municipal level, the values of WM cost per capita and per tonne were calculated. The standard deviations of these datasets for each considered year are outlined in Figure 6. The standard deviation of the cost per tonne indicator had a higher increasing rate before 2012, while after 2013 it seems steadier, showing a higher level of uniformity among the Municipalities. The standard

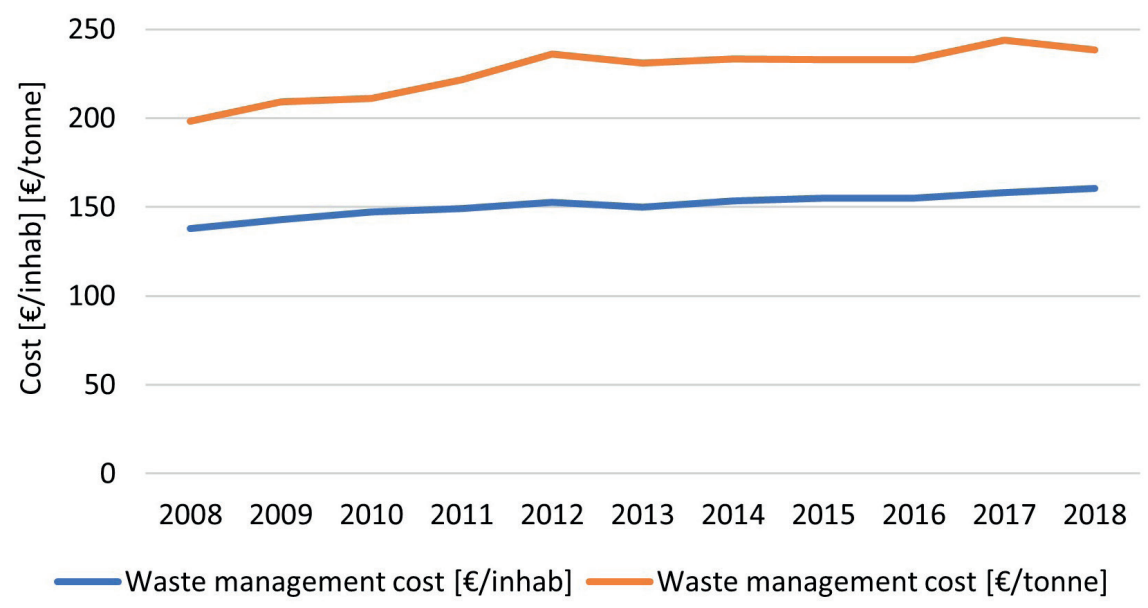

FIGURE 5: Waste management cost in Emilia-Romagna, 2008-2018. Source: authors' elaboration on ATERSIR data. 


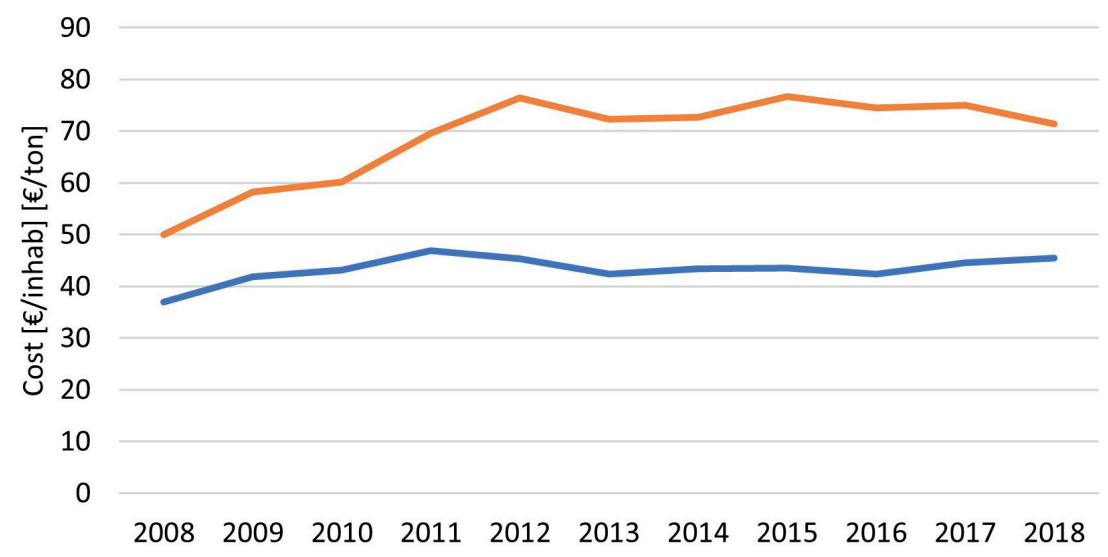

Standard deviation of cost indicator [€/inhab] —Standard deviation of cost indicator [€/tonne]

FIGURE 6: Standard deviation of waste management cost in Emilia-Romagna, 2008-2018. Source: authors' elaboration on ATERSIR data.

deviation of the cost per inhabitant indicator was quite constant over the period of analysis.

Moreover, the variation of per capita WM cost at municipal level was studied, focusing on two time frames: 2008-2012 and 2013-2018. The results show that in the second time frame a lower number of Municipalities had considerable variations in the per capita costs (Figures 7 and 8). This proves a higher homogeneity of the per capita WM cost indicator among Municipalities.

In the two time frames analysed, a different distribution of the cost for each municipality is clearly visible (in the figure, each dot represents a municipality). In particular, in the second Figure (Figure 8) the pattern highlights an extremely minor variability (represented by the higher density of the cloud) and a significant number of municipalities switching on the negative values of the $x$-axis, thus meaning that in those municipalities the total cost has decreased.

\subsubsection{Cost of treatment and disposal of unsorted waste} (CTS)

According to Biagi and Massarutto (2002), CTS is the less transparent cost item, and the one in which, in all likelihood, the main causes of potential market failures are to be found. Moreover, according to the analysis of empirical data of 6,616 Italian municipalities for a two-year period performed by Di Foggia and Beccarello (2020b), waste-to-energy plants and landfills play a remarkable role in WM cost determination. Thus, this in-deep analysis of CTS was considered relevant by the authors.

The average and the standard deviation of the per tonne cost, analysed at municipal level, show that the trend of both indicators over the eleven years was quite stable (Figure 9).

Unfortunately, regarding the fees for access to treatment facilities, there are no national databases which al-

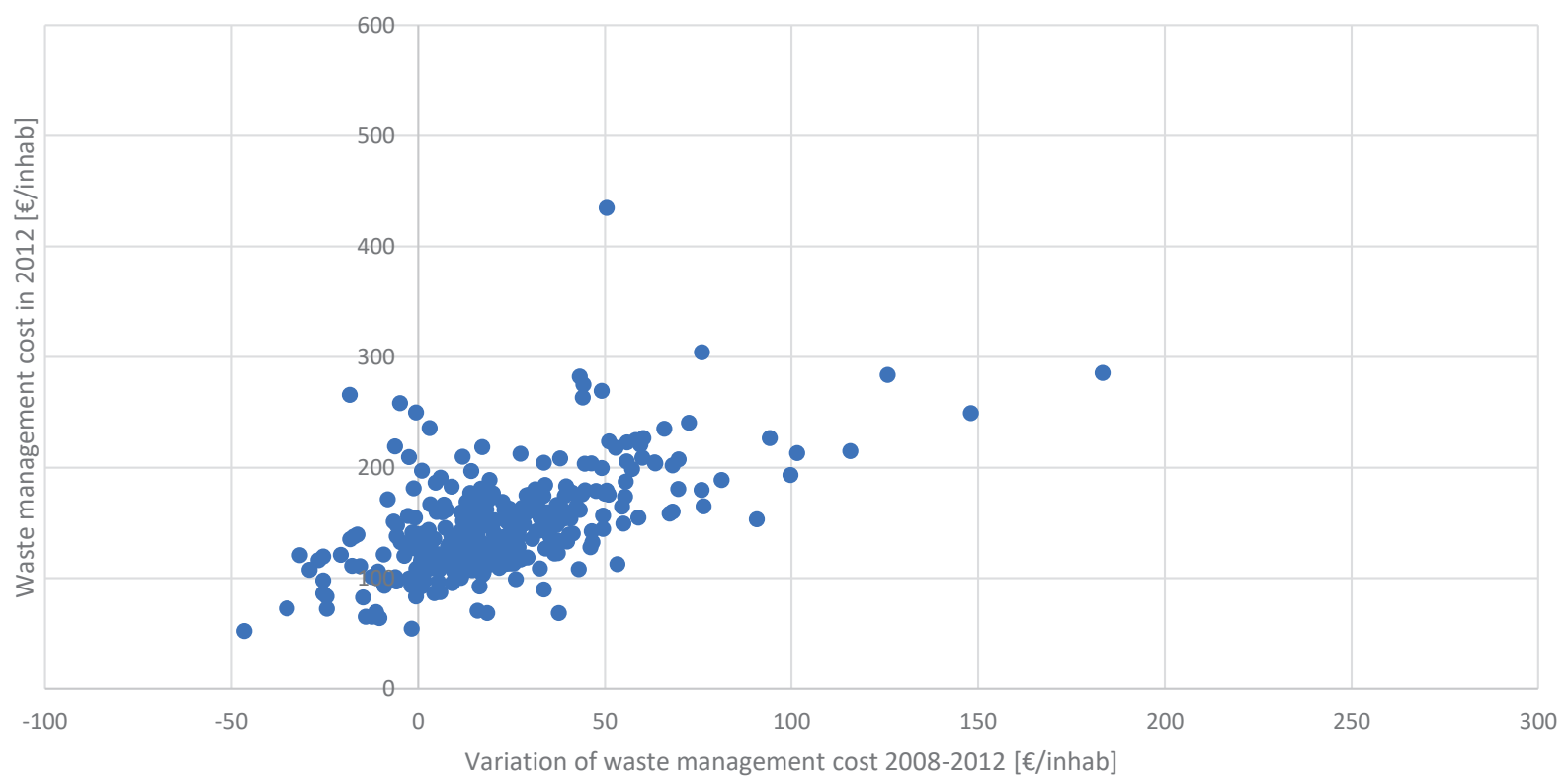

FIGURE 7: Variation of waste management cost (2008-2012) and waste management cost (2012), for each Municipality in the Emilia-Romagna region. A negative variation (x-axis) represents a decrease in the cost over years. Source: authors' elaboration on ATERSIR data. 


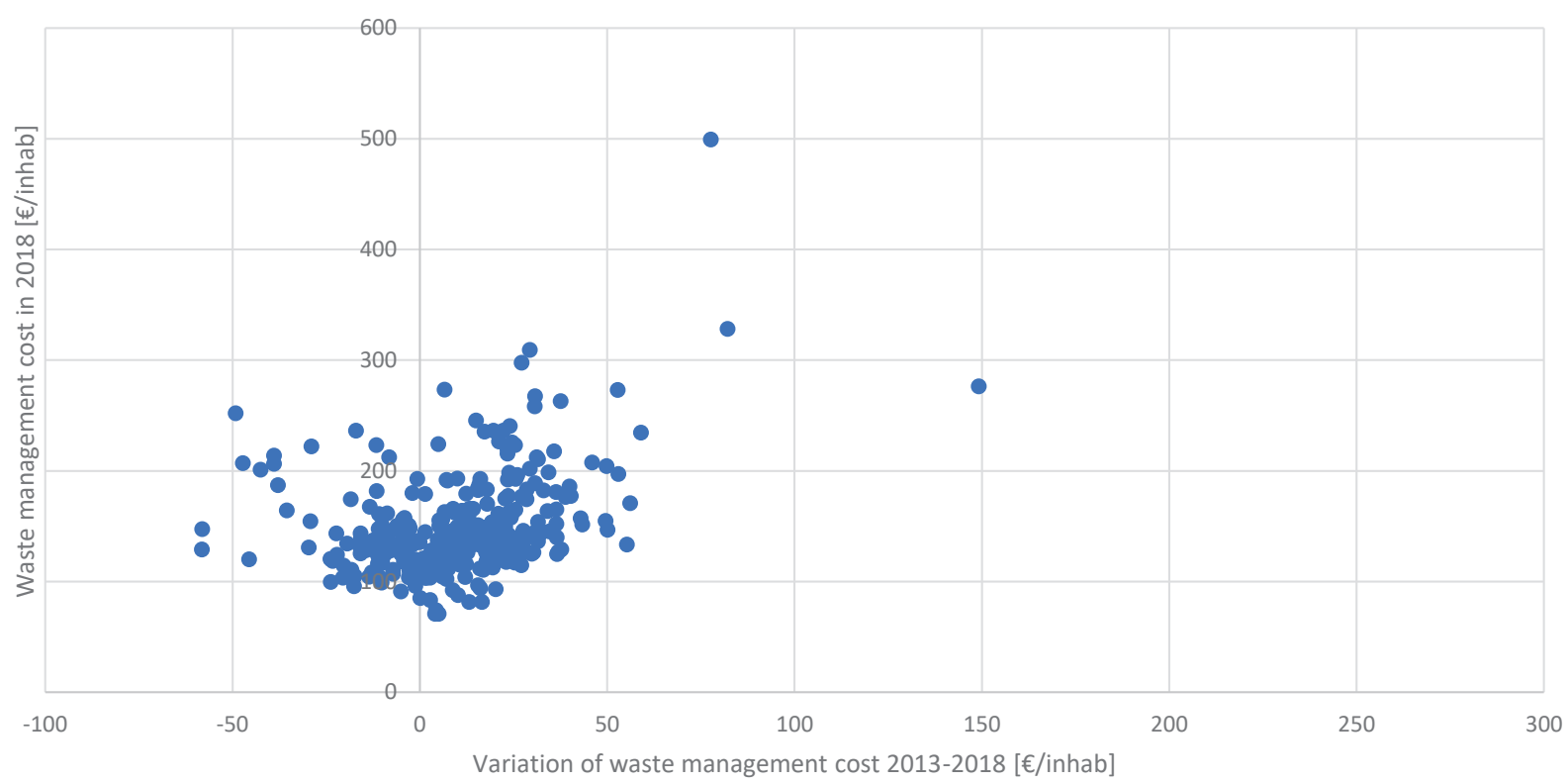

FIGURE 8: Variation of waste management cost (2013-2018) and waste management cost (2018), for each Municipality in the Emilia-Romagna region. A negative variation (x-axis) represents a decrease in the cost over years. Source: authors' elaboration on ATERSIR data.

low one to fully understand how many and which treatment plants are subject to a certain administered rate and how much they apply market prices (ARERA, 2018; Moretto et al., 2019). Therefore, the comparison with the national level was performed by using data from ISPRA. By comparing the standard deviation of the indicator "CTS per tonne" at regional level with the standard deviation of the same indicator assessed in other selected Italian regions, it came to light that in Emilia-Romagna this indicator had a low variability and no peaks (Figure 10). Over the same time frame, the average value was generally lower compared to the one of the other Regions (Figure S18).

Moreover, the variation of per tonne CTS at municipal level was studied. Considering the availability of data, two samples of 299 and 325 Municipalities were object of analysis in the two time frames, respectively. The results show that in the second time frame the variation of CTS was generally and considerably lower.

\subsection{Institutional assessment}

\subsubsection{System of data collection}

A positive consequence of establishing a unique regional Agency is surely the higher capability of data acquisition, harmonization and elaboration (Biagini, 2016). On the other hand, a process of homogenisation of information provided by waste service operators and municipalities to the regulatory authority was required, to enable comparisons among different providers. For this purpose, in 2012 the Regional Council Resolution 754/2012 was issued with the aim of making available to ATERSIR a set of technical, management and economic data describing the entire WM cycle, in a uniform manner throughout the territory and according to fixed reporting templates over time, while avoiding as much as possible the duplication of information required to waste operators.

Thus, the acquired information allowed ATERSIR to create the know-how necessary to perform benchmark analyses, thus supporting the decision-making process and the

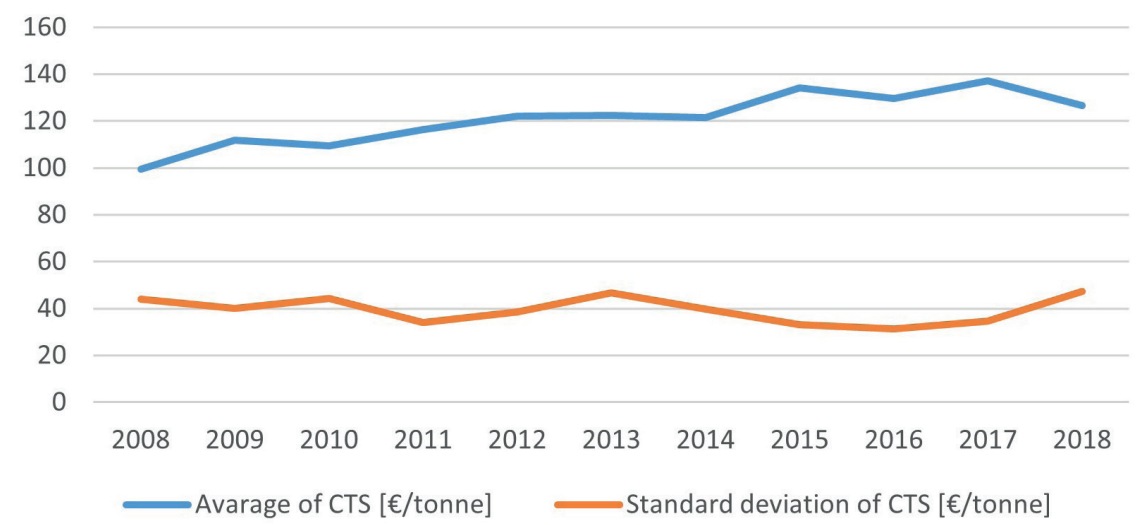

FIGURE 9: Average and standard deviation of cost of treatment and disposal of unsorted waste in Emilia-Romagna, 2008-2018. Source: authors' elaboration on ATERSIR data. 
adoption of the best regulatory policies, and to define the disposal fees.

Every single local authority was previously able to analyse data originated from one to maximum four providers (in the Province with the highest degree of fragmentation). Nowadays, the staff of the regional agency can simultaneously analyse data originated by 12 providers and referred to the whole regional territory.
The so-called information asymmetry, which is intrinsic in the interaction between the regulator and regulated firms, was reduced, compared to the previous situation, and the regulatory body was effectively strengthened.

\subsubsection{Reporting, access to information and waste traceabil-} ity projects

Over time, a regulatory approach on a wider scale made

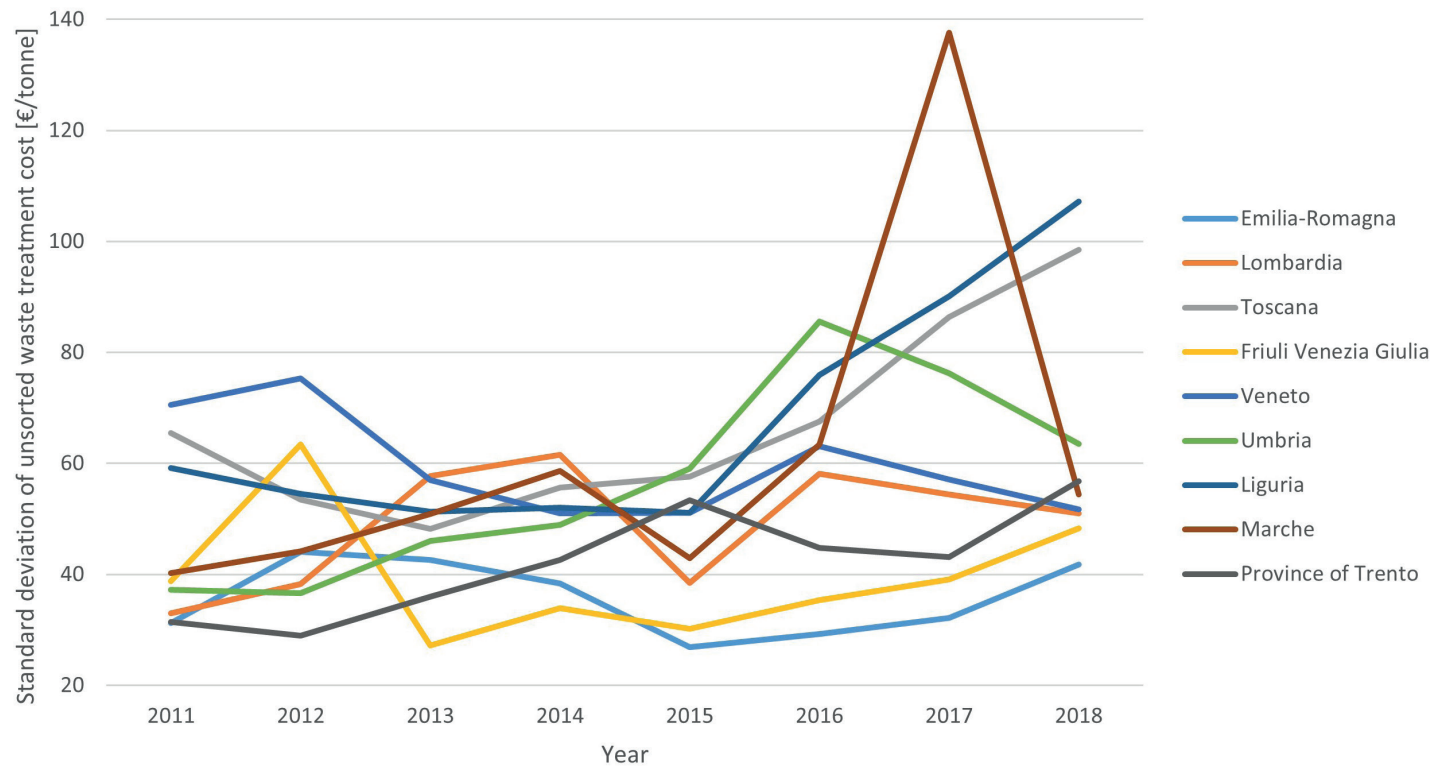

FIGURE 10: Standard deviation of cost of treatment and disposal of unsorted waste (CTS) for some Italian Regions, at municipal level. Source: authors' elaboration on ISPRA, 2019.

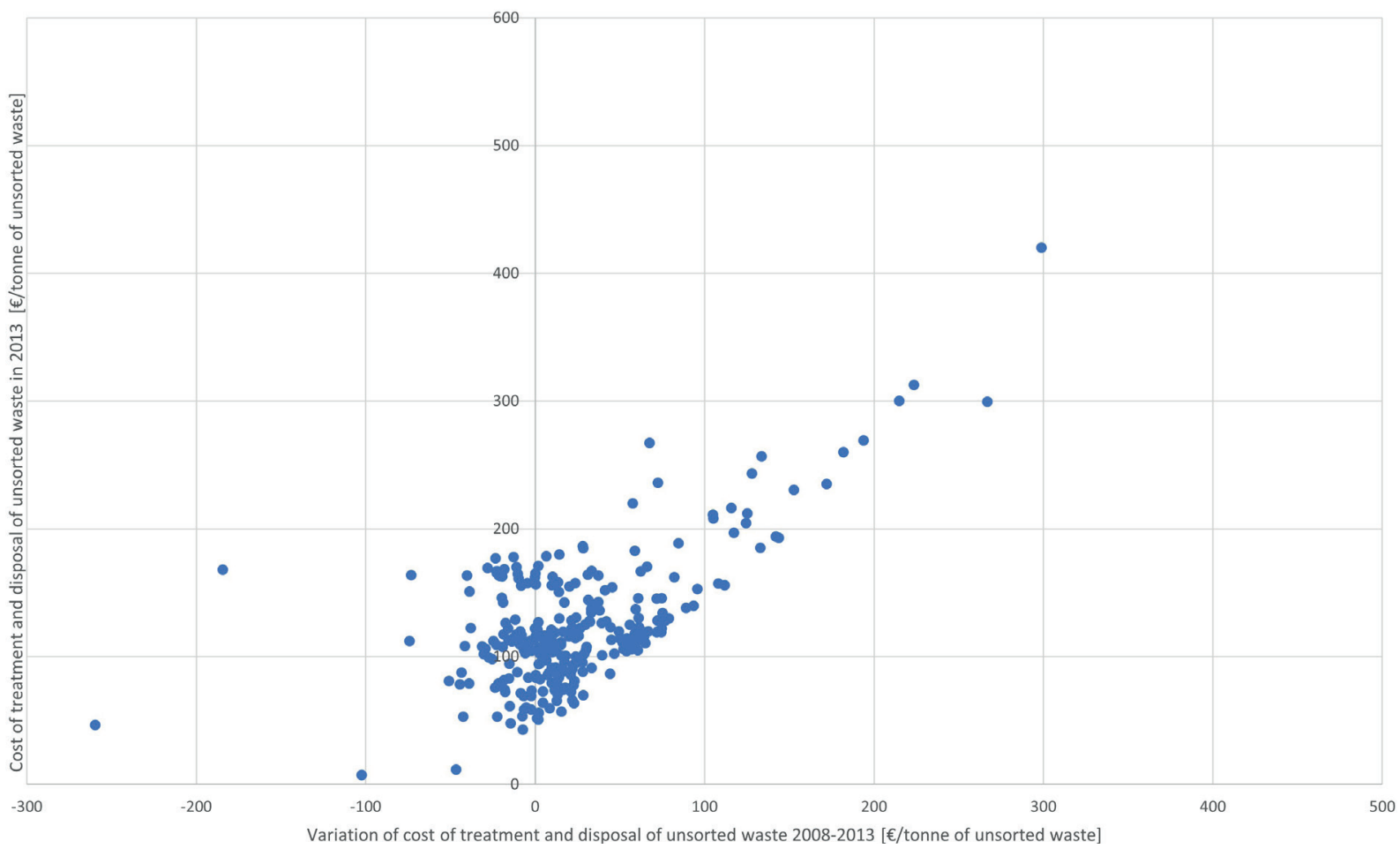

FIGURE 11: Variation of cost of treatment and disposal of unsorted waste (2008-2013) and cost of treatment and disposal of unsorted waste (2013), for each Municipality in the Emilia-Romagna region. A negative variation (x-axis) represents a decrease in the cost over years. Source: authors' elaboration on ATERSIR data. 


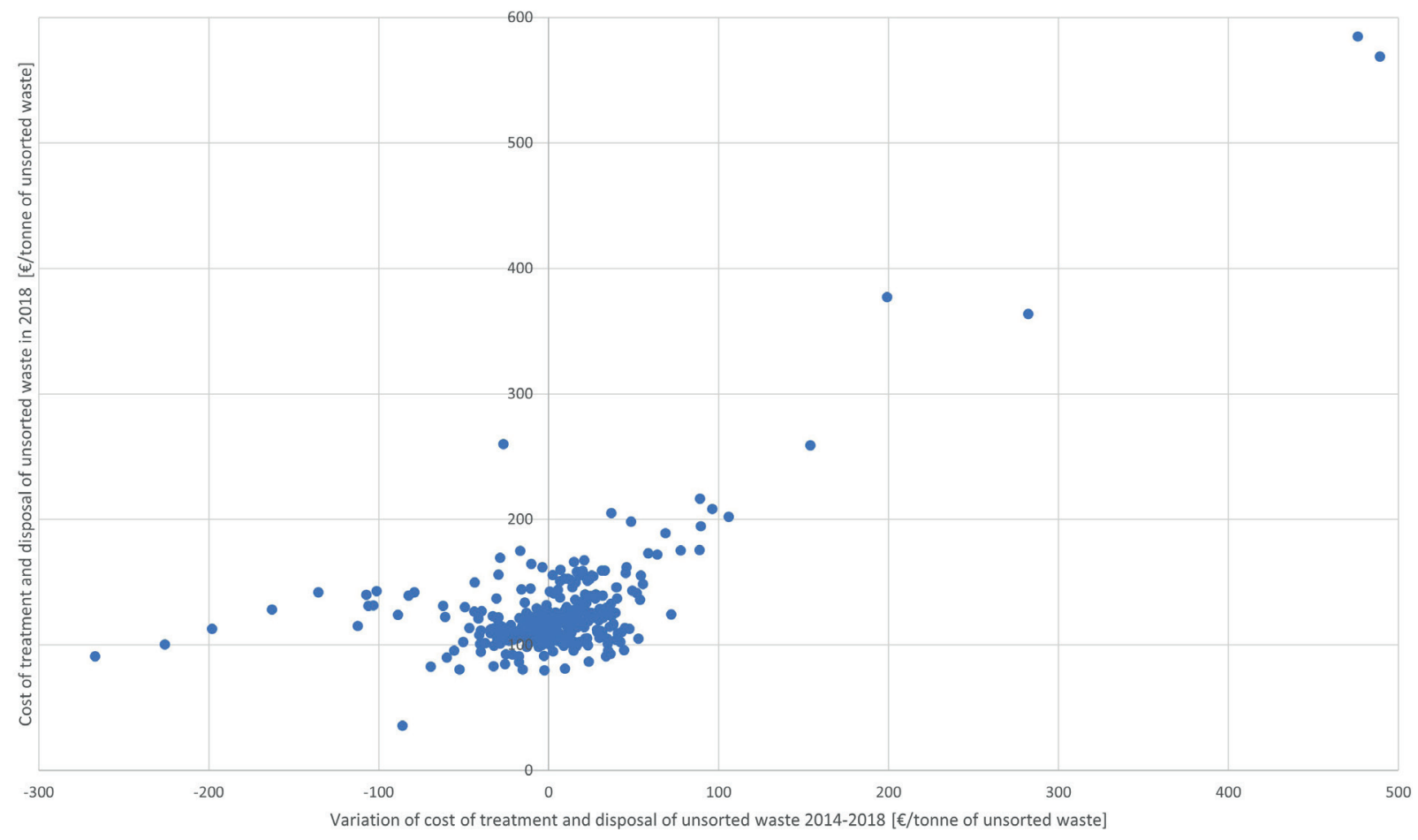

FIGURE 12: Variation of cost of treatment and disposal of unsorted waste (2014-2018) and cost of treatment and disposal of unsorted waste (2018), for each Municipality in the Emilia-Romagna region. A negative variation (x-axis) represents a decrease in the cost over years. Source: authors' elaboration on ATERSIR data.

the different territories comparable, while disclosing uniform information in terms of regional system. The scope of analysis was enlarged, enhancing the reports for citizens with economic analyses.

For example, since 2011, economic analysis of WMS has been included in the annual reports on regional WM, published by ARPAE.

In 2016, the Observatory of WM Plan Cost was set up with the participation of the Region, ATERSIR and ARPAE, with the aim of integrating, monitoring and analysing together territorial, technical and infrastructural information related to the waste service, correlating it to the economic impacts and the effects on users' tariffs.

Another example is the initiative "Chi li ha visti?" ("Who saw them?", translating), which analyses and traces the UW produced annually in the region, retraces the path of some waste flows after separate collection and disseminates data on material recovery, providing a useful tool for monitoring the regional WM plan. The project, carried out by the Region with the collaboration of ARPAE and with the contribution of CONAI (National Packaging Consortium) and based on measured data (Emilia-Romagna region, 2019a), has been conducted since 2009, and was made possible by the regional level of analysis. Emilia-Romagna is the only region where a waste traceability activity is carried out yearly by the public administration.

\subsubsection{Rationalization of waste management plants in the region}

In the previous phase of provincial WM planning, each Province was required to be self-sufficient in WM. This had resulted in a complete, modern, and efficient system of WM plants in the regional territory. The transition to a regional WM planning has led to an optimised management of the plants, avoiding redundancy, having to guarantee self-sufficiency of WM in a larger area.

From 2014 onwards, the region started to plan individual unsorted waste streams to treatment plants, year by year, in compliance with the European waste hierarchy, achieving coordination between collection and disposal. A substantial rationalisation and reduction of plants was allowed by the interoperability between the provincial territories and the dynamic optimisation of the waste flows to existing plants, in compliance with two fundamental principles: the progressive closure of landfills and the self-sufficiency in the management of urban and special waste generated in the region. Moreover, the surplus capacity of WTE plants at regional level is used to treat commercial and business waste (Laboratorio REF Ricerche, 2020), reaching a balance between the need and the overall plant capacity. Thus, Emilia-Romagna is one of the few regions in Italy achieving self-sufficiency. Since the use of WM facilities within the territory (with the exception of mechanical biological treatment) is a significant cost reduction driver ( $\mathrm{Di}$ Foggia and Beccarello, 2020b), self-sufficiency in WM capacity contributes also to the economic sustainability of the service.

\subsubsection{Waste management service entrustment}

One of the main tasks of ATERSIR is to contract out the waste service, according to the methodologies accepted by the European legislation, i.e. in-house providing society, 
public-private partnership and international call for tender.

Particularly, the decision to proceed to public international competitive tendering procedures for service entrustment is an important innovation in this field, considering the traditional in-house management of these services, directly provided by public-owned companies.

All the decisions about service entrustment, included the form of the concession commitment, have been carried out in close agreement with the municipalities.

While almost all the previous service concession contracts lasted until the end of 2011 and the end of 2014, and nothing had been decided by the former 9 provincial authorities about how to entrust the service, ATERSIR in the years between 2012 and 2018 arranged three different new in-house providing concessions and published three calls for tender, concerning three different areas. Still, as this paper is being written, the Agency is trying to entrust the MSW service in all the basins where the concession contract is expired.

Probably, the previous, local, administrations (grouped in the former provincial authorities) could have been weaker in contracting out the service, in designing a tender or in analysing and managing the real effectiveness and efficacy of self-owned companies, demonstrating the concrete risk of the regulatory capture both by the political instances and industrial interests (Armstrong and Sappington, 2006).

\subsubsection{Standard guidelines for the Municipalities}

After 2012, the regional and centralised governance allows the development of standardised guidelines and operating procedures, with practical implications for Municipalities. For example, in 2018 standard rules for the definition of the waste fees in PAYT systems were issued (ATERSIR, 2018; Emilia-Romagna Region, 2018; Emilia-Romagna Region, 2019b). The Region has also regulated the activity of reuse centres through the guidelines for municipal and non-municipal reuse centres (Emilia-Romagna Region, 2017). Moreover, in 2019 uniform procedures to facilitate the removal of small amounts of asbestos-containing material from a compact matrix were defined (Emilia-Romagna Region, 2019c).

\section{CONCLUSIONS}

This study provides an integrated analysis of waste services in the Emilia-Romagna region over the period 20082018, considering three dimensions of sustainability (environmental, economic, and institutional). Environmental and economic data were gathered and analysed at regional and municipal level, considering different time frames, before and after the institutional reform which unified the provincial ATOs in one unique regional ATO.

The institutional assessment has taken into account the different institutional levels and how this new division of roles has impacted on decision-making and planning processes.

Since the providers of waste services are the same over the analysed period, it can be assumed that the variations have to be ascribed to changes in policies, regulations, and governance.
While some improvements in environmental performances might be a consequence of a stricter regulation at European and national level, the authors claim that better and more homogeneous performances resulted from a centralised regulation at regional level, pursuing circular economy strategies. Furthermore, according to the paragraph 4.3.3, the dynamic optimisation of the waste flows to existing plants allowed a substantial rationalisation and reduction of plants, besides a considerable minimisation of landfill use as final destination, favouring the shift towards energy recovery of unsorted waste.

Thanks to the economic regulation, an increased homogeneity of economic variables among Municipalities was fulfilled, both considering total WM cost and CTS, according to a specific regional regulation. This result is confirmed by the comparison with other Italian regions. The authors claim that the increased territorial scope of the regulatory authority contributed to this result, by enabling data collection from different data sources and benchmark among a higher number of waste service providers.

As far as the contracts granted to MSW providers are concerned, the regional level seems to be more suitable to these kinds of decisions than the previous provincial one. The decision process about the waste service entrustment guarantees the safeguard of municipalities instances, but in full compliance with a stronger independence of the regulatory agency.

Thanks to the centralisation of the regulation, more complete reports on waste management were made available for citizens and uniform information were disclosed to public.

The results of the environmental assessment show that prevention of UW is not completely fulfilled at regional level, although the commitment of the region to prevention and reuse is strong. This evidence suggests that waste prevention is a long-term process, affected by multiple exogenous factors (firstly, cultural habits and industrial design, in the authors' opinion). Long term policies and step-by-step improvements are required to achieve actual results.

A focus on the transition to PAYT systems should be done by policy makers, in this framework about prevention policies. Even though the first results from the municipalities in which PAYT systems have been implemented suggest that per capita waste production is $10 \%-15 \%$ lower than the average production in the region, the regional target on waste production (set in the regional WM plan) is far from being achieved. Moreover, the effectiveness of PAYT schemes on waste reduction seems to be mostly affected by how the system is designed (Magrini et al., 2020).

On the other hand, waste production and treatment concern regional policies which have to be incentivised and integrated in different production sectors and actors, firstly including waste service providers. Moreover, thanks to the transition to a regional OTA, the policies on WM and planning might be better integrated in policies about other topics of regional responsibility, e.g. industrial policy, urban policy, tourism management, in a circular economy approach. National guidelines could help in this process, leading to a more standardized policy framework. As already claimed by OECD (2020), to achieve circular econo- 
my goals, subnational governments need to be supported by an enabling framework that national governments can establish effectively.

Besides the existing target at Municipal level on separate waste collection rate, monitoring waste production at Municipal level could be useful to increase the awareness of the local level on waste prevention. The parameter "Inhabitant Equivalent" might be used in order to make comparable the different Municipalities, to provide a more detailed analysis and to support the policy-makers.

A national multidisciplinary approach could also lead to the chance of comparing different regions, both for analyses concerning waste production and prevention, and for economic and financial analyses. In this respect, the implications from the recent institution of ARERA (in 2018) should be discussed in further research studies. Indeed, different regulatory models are in place in Italy: this highlights that efficiency and economies of scale/scope/density are not the only criteria impacting on this decision, but the political context plays a role.

Despite the institutional transition described in this paper, economic and waste service characteristics are still quite affected by decisions at municipal level because of the legislative competences of Municipalities in some fields, such as in the tariffs management, the essence of users charges and the adoption of municipal guidelines. The balance of these competences with a more industrial approach to the MSW management is still challenging.

\section{ACKNOWLEDGEMENTS}

The authors acknowledge the support of ATERSIR. Opinions expressed in this paper by the authors are the personal opinions of the authors alone and do not necessarily represent the views of the organisations they work for.

\section{REFERENCES}

Abrate, G., Erbetta, F., Fraquelli, G., \& Vannoni, D., 2014. The Costs of Disposal and Recycling: An Application to Italian Municipal Solid Waste Services. Regional Studies, 48(5), 896-909. http://doi.org/ 10.1080/00343404.2012.689425

Al-Najjar, N. I., 1998. A reputational model of authority, Center for Mathematical Studies in Economics and Management Sciences, Discussion Paper, 1223.

Antonioli, B., Filippini, M., 2002. Optimal size in the waste collection sector. Review of Industrial Organization, 20(3), 239-252. http:// doi.org/10.1023/A:1015043524679

Antonioli B., Massarutto A., 2011. The municipal waste management sector in Europe: shifting boundaries between public service and the market. CIRIEC working papers 1107, CIRIEC - Université de Liège. Available at: http://www.ciriec.uliege.be/repec/WP11-07. pdf (accessed on 27th July 2020)

ARERA, 2018. Consultation 27 December 2018 713/2018/R/rif. Criteri per la determinazione dei corrispettivi del servizio integrato di gestione dei rifiuti urbani e assimilati e dei singoli servizi che costituiscono attività di gestione. Available at https://www.arera.it/it/ docs/18/713-18.htm (accessed on 22nd July 2020)

Armstrong, M., Sappington, D.E.M., 2006. Regulation, competition, and liberalization. Journal of Economic Literature, $44,325-366$. DOI: $10.1257 /$ jel.44.2.325

ATERSIR, 2018. Resolution of ATERSIR regional board n. 75, 8 November 2018, Servizio Gestione Rifiuti. Approvazione del Regolamento tipo per la disciplina della tariffa rifiuti corrispettiva in attuazione del protocollo di intesa tra Regione Emilia-Romagna, $\mathrm{ANCl}$ ed Atersir in materia di tariffazione puntuale.
Biagi, F., Massarutto, A., 2002. Efficienza e regolamentazione nei servizi pubblici locali: il caso dell'igiene urbana. Economia Pubblica n.2, 79-115.

Biagini, G., 2016. A Regulatory Multi-Level Reform in Italian Urban Waste Service Management: From Several Local Regulatory Agencies to a Unique Regional One, in: Asquer, A., Becchis, F., Russolillo, D., The Political Economy of Local Regulation- Theoretical Frameworks and International Case Studies.

Campitelli, A., Schebek, L., 2020, How is the performance of waste management systems assessed globally? A systematic review, Journal of Cleaner Production, 272, https://doi.org/10.1016/j.jclepro.2020.122986.

Carvalho, P., Marques, R.C., 2014. Economies of size and density in municipal solid waste recycling in Portugal, Waste Management, 34, 1, 12-20, https://doi.org/10.1016/j.wasman.2013.10.004.

Carvalho, P., Marques, R.C., Dollery, B., 2015. Is bigger better? An empirical analysis of waste management in New South Wales. Waste Manage. 39, 277-286. https://doi.org/10.1016/j.wasman.2015.01.024.

CNEL, 2019. Relazione 2019 al Parlamento e al Governo sui livelli e la qualità dei servizi offerti dalle Pubbliche amministrazioni centrali e locali alle imprese e ai cittadini. Available at: https://www.cnel.it/ Portals/0/CNEL/Rapporti_Relazioni_Documenti_per_sito/Relazione_Qualit\%C3\%A0_gennaio_2020/Relazione_Qualit\%C3\%A0_PA_ CNEL_2019_def.pdf?ver=2020-01-21-091939-187 (accessed on 27th July 2020).

Decree of the President of Italian Republic n. 158, 27 aprile 1999. "Regolamento recante norme per la elaborazione del metodo normalizzato per definire la tariffa del servizio di gestione del ciclo dei rifiuti urbani".

Di Foggia, G., Beccarello, M., 2020a. The impact of a gain-sharing cost-reflective tariff on waste management cost under incentive regulation: The Italian case. J Environ Manage. Jul 1;265:110526. doi: 10.1016/j.jenvman.2020.110526.

Di Foggia, G., Beccarello, M., 2020b. Drivers of municipal solid waste management cost based on cost models inherent to sorted and unsorted waste, Waste Management, 114, 202-214,https://doi. org/10.1016/j.wasman.2020.07.012.

Emilia-Romagna Region, 2011. Regional Law n. 23, 23 December 2011. "Norme di organizzazione territoriale delle funzioni relative ai servizi pubblici locali dell'ambiente".

Emilia-Romagna Region, 2012. Regional Council Resolution n. 754, 11 June 2012. "Approvazione delle linee guida per la rendicontazione del servizio di gestione rifiuti urbani e assimilati in Emilia-Romagna ai sensi del l'art. 12, comma 1, lettere a), b), c) e g), della legge regionale $\mathrm{n} .23$ del 2011".

Emilia-Romagna Region, 2013. Regional Council Resolution n. 135, 11 February 2013. "Disposizioni relative alla determinazione del corrispettivo per lo smaltimento dei rifiuti urbani e assimilati di cui all'art.16, comma 1, della L.R. 23/2011 ed aggiornamento della direttiva "Linee guida per la rendicontazione del servizio di gestione dei rifiuti urbani e assimilati in Emilia-Romagna" di cui alla D.G.R. 754/2012"

Emilia-Romagna Region, 2014. Regional Council Resolution n. 380, 24 March 2014. "Modificazioni alla DGR n. 135/13 - Disposizioni in materia di definizione e gestione del limite di incremento del corrispettivo per lo smaltimento dei rifiuti urbani".

Emilia-Romagna Region, 2015a. Regional Law n.16, 5 October 2015. "Disposizioni a sostegno dell'economia circolare, della riduzione della produzione dei rifiuti urbani, del riuso dei beni a fine vita, della raccolta differenziata e modifiche alla legge regionale 19 agosto 1996 n. 31 (disciplina del tributo speciale per il deposito in discarica dei rifiuti solidi)".

Emilia-Romagna Region, 2015b. Regional Council Resolution n. 467, 27 April 2015. "Criteri per la determinazione del corrispettivo per lo smaltimento dei rifiuti urbani e assimilati ai sensi dell'art. 16, comma 1, della L.R. n. 23 del 2011"

Emilia-Romagna Region, 2016. Legislative Assembly Resolution n. 67, 3 May 2016. "Waste management plan of Emilia-Romagna Region". Available at: http://ambiente.regione.emilia-romagna.it/ rifiuti/temi/piano-rifiuti (accessed on 22nd July 2020).

Emilia-Romagna Region, 2017. Regional Council Resolution n. 1382, 25 September 2017. "Linee guida regionali per i centri del riuso comunali e non comunali".

Emilia-Romagna Region, 2018. Regional Council Resolution n. 1762, 22 October 2018. "Regolamento tipo per la disciplina della Tariffa Corrispettiva puntuale (TCP): presa d'atto dei lavori del Comitato Guida per l'attuazione del Protocollo di Intesa tra Regione Emilia-Romagna, ATERSIR ed ANCI in materia di tariffazione puntuale 
Emilia-Romagna Region, 2019a. Chi li ha visti. Available at: https:// ambiente.regione.emilia-romagna.it/it/rifiuti/informazioni/Iniziative-comunicazione/chi-li-ha-visti-le-passate-edizioni (accessed on 22nd July 2020)

Emilia-Romagna Region, 2019b. Regional Council Resolution n. 2025 18 November 2019 "Regolamento tipo per la disciplina della TARI tributo puntuale (TTP): presa d'atto dei lavori del Comitato Guida per l'attuazione del Protocollo di Intesa tra Regione Emilia-Romagna, ATERSIR ed ANCI in materia di tariffazione puntuale"

Emilia-Romagna Region, 2019c. Regional Council Resolution n. 1071 1 July 2019. "Approvazione delle Linee Guida per la microraccolta dell'amianto- Azione 6.2.1.3 del Piano Amianto della Regione Emilia-Romagna (Promuovere procedure semplificate per la rimozione e smaltimento di piccole quantità di MCA in matrice compatta)"

Eurostat, 2019. Primary income of private households by NUTS 2 regions. Available at: https://ec.europa.eu/eurostat/databrowser/ product/view/TGS00036?lang=en (accessed on 22nd July 2020)

Filho, W.L., Brandli, L., Moora, H., Kruopienè, J., Stenmarck, A., 2016. Benchmarking approaches and methods in the field of urban waste management, Journal of Cleaner Production, 112, Part 5, 4377-4386, https://doi.org/10.1016/j.jclepro.2015.09.065.

Hellweg, S., Canals, L.M., 2014. Emerging approaches, challenges and opportunities in life cycle assessment. Science, 344, 1109-1113.

Hoornweg, D., Bhada-Tata, P., 2012. What a waste: a global review of solid waste management. Urban development series; knowledge papers no. 15. World Bank, Washington, DC. (c) World Bank. Available at: https://openknowledge.worldbank.org/handle/10986/17388 (accessed on 22nd July 2020)

Invitalia, 2019. Monitor-SPL ASSETTI ORGANIZZATIVI E GESTIONALI DEL SERVIZIO RIFIUTI URBANI Report nazionale. Available at: https://reopenspl.invitalia.it/banche-dati/monitor-spl/monitor-rifiuti

Italian Government, 2006. Legislative decree n. 152, 3 April 2006. Norme in materia ambientale

ISPRA, 2019. Costi di gestione dei servizi di igiene urbana. Available at: https://www.catasto-rifiuti.isprambiente.it/index.php?pg=menucostiru (accessed on 28th January 2021)

ISPRA, 2020a. Produzione e raccolta differenziata dei rifiuti urbani. Available at: https://www.catasto-rifiuti.isprambiente.it/index. php?pg=menuprodru

ISPRA, 2020b. Pubblicazioni in materia di contabilità dei rifiuti. Available at: https://www.catasto-rifiuti.isprambiente.it/index.php?pg=pubblicazioni (accessed on 22nd July 2020)

Laboratorio REF Ricerche, 2020. La responsabilità delle scelte: i fabbisogni impiantistici e il ruolo delle regioni.

Magrini, C., D'Addato F., Bonoli A., 2020. Municipal solid waste prevention: A review of market-based instruments in six European Union countries, Waste management \& research, 38. https://doi. org/10.1177/0734242X19894622

Magrini, C., Degli Esposti, A., De Marco, E., Bonoli, A., 2021. A framework for sustainability assessment and prioritisation of urban waste prevention measures, Science of the Total Environment https://doi.org/10.1016/j.scitotenv.2021.145773
Marques, R.C., Simões P., 2009. Incentive regulation and performance measurement of the Portuguese solid waste management services Waste Manage. Res., 27, pp. 188-196, $10.1177 / 0734242 \times 08095025$

Marques, R.C., Simões, P., Pinto, F., 2018. Tariff regulation in the waste sector: An unavoidable future, Waste Management,78,292-300. https://doi.org/10.1016/j.wasman.2018.05.028

Massarutto, A., 2010. Municipal waste management in Italy, CIRIEC working paper N. 2010/01. Available at: http://www.ciriec.uliege. be/wp-content/uploads/2015/11/WP10-01.pdf (accessed on 22nd July 2020)

Moretto, A., Favot, M., Massarutto A., 2019. Economic regulation of the waste management sector: defining an efficient benchmark of the gate fees of treatment plants. Innovations \& technologies in waste recovery, proceedings of 4th MatER Meeting, Piacenza, Italy, 27-29 May 2019

OECD, 2020. The Circular Economy in Cities and Regions. Synthesis Report. https://doi.org/10.1787/b261814f-en

Passarini, F., Vassura, I., Monti, F., Morselli, L., Villani, B., 2011. Indicators of waste management efficiency related to different territorial conditions. Waste Management 31(4):785-792. doi:10.1016/j. wasman.2010.11.021

Sarra, A., Mazzocchitti, M., Rapposelli, A., 2017. Evaluating joint environmental and cost performance in municipal waste management systems through data envelopment analysis: scale effects and policy implications. Ecological Indicators $73 \mathrm{https} / / /$ doi. org/10.1016/j.ecolind.2016.10.035

Sarra, A., Mazzocchitti, M., Nissi, E., 2020. Optimal regulatory choices in the organization of solid waste management systems: Empirical evidence and policy implications. Environmental Science \& Policy, 114, 436-444, https://doi.org/10.1016/j.envsci.2020.09.004.

Stevens, B., 1978. Scale, Market Structure, and the Cost of Refuse Collection. The Review of Economics and Statistics, 60(3), 438-448

Simões, P., Marques, R.C., 2012a. Influence of regulation on the productivity of waste utilities. What can we learn with the Portuguese experience? Waste Manage., 32 (2012), pp. 1266-1275, 10.1016/j. wasman.2012.02.004

Simões, P., Marques, R.C. 2012b. On the economic performance of the waste sector. A literature review.

J. Environ. Manage., 106 (2012), pp. 40-47, 10.1016/j.jenvman.2012.04.005

Simões, P., Cavalho, P., Marques, R.C., 2013. The market structure of urban solid waste services: how different models lead to different results. Local Gov. Stud. 39, 396-413. https://doi.org/10.1080/03 003930.2013 .783477

Tanguy, A., Villot, J., Glaus, M., Laforest, V., Hausler, R., 2017. Service area size assessment for evaluating the spatial scale of solid waste recovery chains: A territorial perspective, Waste Management, 64, 386-396, https://doi.org/10.1016/j.wasman.2017.03.027. 